\title{
A review of Genetic Programming and Artificial Neural Network applications in pile foundations
}

\author{
Milad Fatehnia ${ }^{1,2^{*}}$ (1) and Gholamreza Amirinia ${ }^{1}$
}

*Correspondence:
mfatehnia@fsu.edu
${ }^{2}$ ECS Southeast, LLP, Marietta,
GA 30066, USA
Full list of author information
is available at the end of the
article

${ }^{*}$ Correspondence:

mfatehnia@fsu.ed

GA 30066, USA

is available at the end of the

article

\begin{abstract}
Uncertainty in the behavior of geotechnical materials (e.g. soil and rock) is the result of imprecise physical processes associated with their formation. This uncertainty provides complexity in modeling the behavior of such materials. The same condition is applied to the behavior of the structural elements dealing with them. In this regard, pile foundations, as the structural elements used to transfer superstructure loads deep into the ground, are subjected to these material uncertainties and modeling complexity. Artificial Intelligence (Al) has demonstrated superior predictive ability compared to traditional methods in modeling the complex behavior of materials. This ability has made Al a popular and particularly amenable option in geotechnical engineering applications. Genetic Programming (GP) and Artificial Neural Network (ANN) are two of the most common examples of Al techniques. This paper provides a review of GP and ANN applications in estimation of the pile foundations bearing capacity.
\end{abstract}

Keywords: Pile foundation, Artificial Intelligence (Al), Artificial Neural Network (ANN), Genetic Programming (GP)

\section{Introduction}

Artificial Intelligence (AI) is a scientific discipline that is concerned with the design and development of algorithms used to evolve behaviors based on empirical data. Genetic Programming (GP) and Artificial Neural Network (ANN) are two common examples of AI techniques.

Pile foundations are structural elements that are used to transfer superstructure loads deep into the ground [1]. Several methods for estimating pile bearing capacity are proposed. These include experimental, numerical and analytical methods [2, 3]. Since the interaction of pile foundations and soils is complex and not entirely understood, the applicability of these methods in predicting the bearing capacity of pile foundations is limited. This complex interaction has encouraged researchers to apply AI techniques to predict the ultimate bearing capacity of pile foundations.

The primary focus of this paper is to briefly explain the ANNs and GP techniques and provide a literature review on the application of these methods in predicting the ultimate bearing capacity of pile foundations. 


\section{Overview of artificial intelligence}

Artificial intelligence is a scientific discipline focused on the design and development of algorithms used to evolve behaviors based on empirical data. AI techniques can be used in solving engineering problems [4-11] even if the underlying relationships are unknown or the physical meaning is difficult to explain. This is one of the main advantages of these techniques when compared to most physically-based empirical and statistical methods. AI has the capability of learning by examples of data inputs and outputs presented to them so that the subtle functional relationships among the data are captured. Thus, AI models do not require numerous assumptions about the physical behavior of the system and mainly rely on the data to determine the structure and parameters that govern a system. This is in contrast to most physically-based models that use physical laws to derive the underlying relationships of the system and require prior knowledge about the nature of the relationships among the data. Therefore, AI-based solutions can often provide valuable alternatives for efficiently solving problems in the geotechnical engineering.

AI uses available data to map between the system inputs and the corresponding outputs using machine learning. Mapping process is done by repeatedly presenting examples of the inputs and model outputs in order to find the function that minimizes the error between the actual outputs and the predictions of the AI model. Statistical regression analysis of data with non-linear relationship can be applied successfully only if prior knowledge of the nature of the non-linearity exists. However, for AI models, this prior knowledge of the nature of the non-linearity is not required. In the broad area of engineering problems, it is likely to encounter complex and highly non-linear conditions where traditional regression analyses are inadequate [12].

There are several AI algorithms; amongst them ANN and GP are more applicable for prediction of non-linear phenomena in engineering problems. A brief overview of these techniques is presented below.

Artificial Neural Networks were first introduced by McCulloch and Pitts [13]. ANN as described by Bendana et al. [14] is a massively parallel distributed processor which can store information taken from a data set that is supplied out of the network.

Artificial Neural Networks are computational models based on the information processing system of the human brain and nervous system [15]. They can be considered as a group of simple, highly interconnected elements that process the information by their dynamic state response to external inputs. ANNs learn from data examples presented to them. Because of this, they can be used even if the underlying relationships among the data are unknown or the physical meaning is difficult to explain. Comparing this capability with other traditional empirical and statistical methods which require prior knowledge about the nature of the relationships reveals the applicability of this method in modeling the complex behaviors between inputs and outputs [16]. Since the early 1990s, ANNs have been applied successfully to almost every problem in engineering.

A typical structure of ANNs is composed of a number of interconnected processing elements, commonly referred to as neurons. The neurons are logically arranged in layers that interact with each other via weighted connections. The main three set of layers include input layer, hidden layers, and output layer. Each neuron is connected to all the neurons in the next layer. Patterns are presented to the network via the input layer. This layer communicates to one or more hidden layers where the actual processing is done 
via a system of weighted connections. The hidden layers enable these networks to represent and compute complicated associations between inputs and outputs. The hidden layer subsequently links to an output layer which holds the response of the network to the input. In addition, there is also a bias with modifiable weighted connections, which is only connected to neurons in the hidden and output layers. ANNs can be autonomous and learn by input from outside "teachers" or even self-teaching from written in rules [6]. Typical structure and operation of ANNs is shown in Fig. 1.

The overall performance of the ANN model can be assessed by several criteria including coefficient of determination $\left(R^{2}\right)$, mean squared error, mean absolute error, minimal absolute error, and maximum absolute error. A well-trained model should result in $R^{2}$ value close to 1 and small values of error terms [15].

Genetic Programming is an example of AI inspired by biological evolution extending from genetic algorithms. It can be considered as an evolutionary algorithm-based methodology used to find computer programs that perform a given computational task [6]. The technique was introduced by Koza [18] as a domain-independent problem-solving approach in which computer programs composed of functions and terminals are evolved to solve, or approximately solve, problems by generating a structured representation of the data. The structural representation imitates the biological evolution of living organisms, and emulates naturally occurring genetic operations. The ability to provide the relationship between a set of inputs and the corresponding outputs in a simple mathematical form accessible to the users is the main advantage of the GP over the ANNs.

The first step of GP modelling is the creation of initial population of computer models (also called chromosomes). The initial population includes a randomly selected set of functions and terminals defined by the user to suit a certain problem. The functions and terminals represent the building blocks of the GP models and are arranged in a treelike structure to form a computer model that contains a root node, branches of functional nodes, and terminals (Fig. 2). Examples of functions and terminals used in GP are standard arithmetic operations, Boolean logic functions, trigonometric functions, numerical constants, logical constants, variables, and user-defined operators [19].

Analysis in GP starts with determining a set of functions that represent the nature of the problem or data. Each individual in the population receives a measure of its fitness in the current environment. The fitness criteria are calculated by the objective function i.e., how good the individual is at competing with the rest of the population.

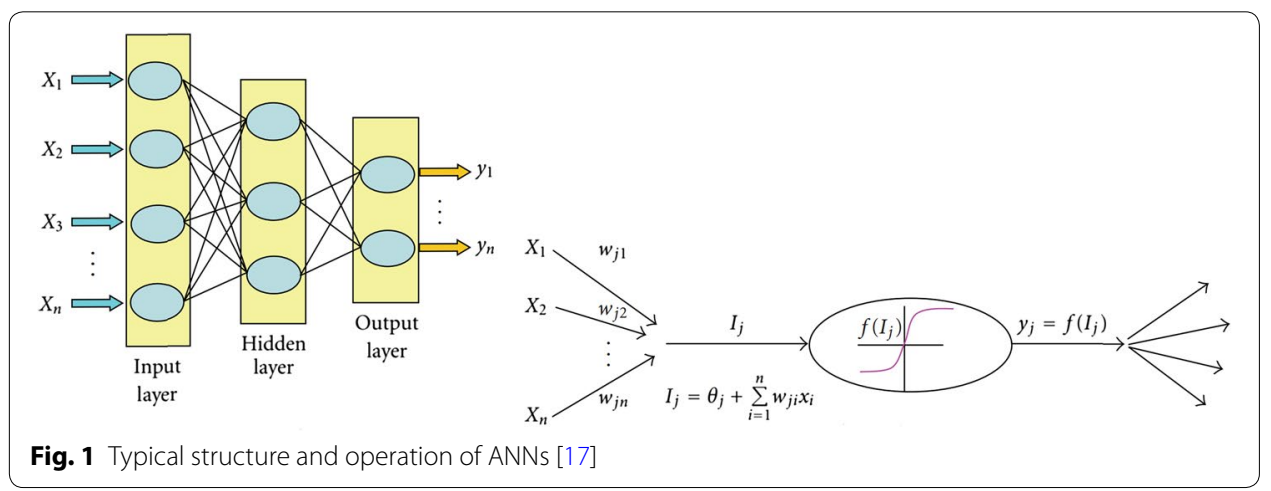




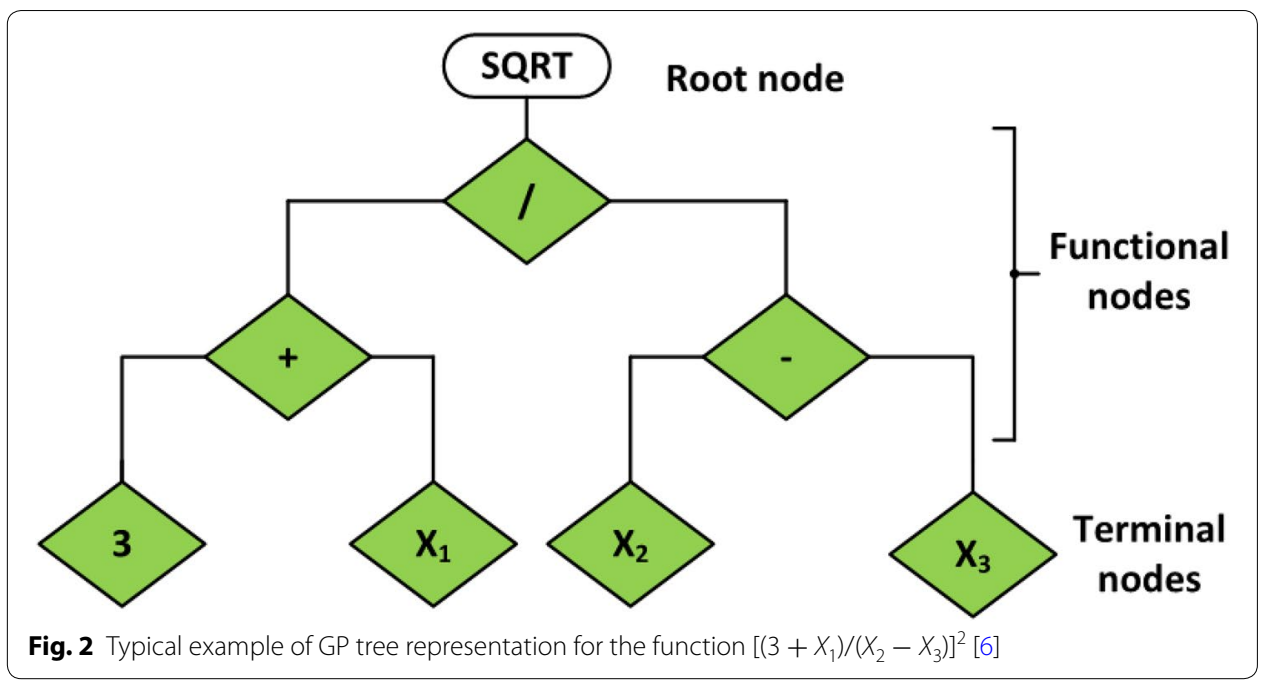

New population is created by applying reproduction, cross-over, and mutation to certain proportions of the computer models. Reproduction is the copying of a computer model from an existing population into the new population without any change; crossover, as shown in Fig. 3, is the genetic recombining of randomly chosen parts of two computer models; and mutation is the replacement of a randomly selected functional or terminal node with others from the same function or terminal set. The existing population will then be replaced with the new population. This evolutionary process is continued until a termination criterion is met, which can be either an acceptable error or a maximum number of generations. Finally, the best computer model is generated by GP using the fitness function adopted.

\section{Al applications in bearing capacity prediction of pile foundations}

This section provides an overview of the applications of ANNs and GP in prediction of the bearing capacity of pile foundations. It should be noted that covering every single application of these techniques in pile foundations is not intended in the current paper. However, the intention is to provide a general overview of some of the more relevant applications in pile foundation's bearing capacity estimation. In order to be able to compare the previous applications and analyze their findings, an overview of the following variables is studied: selected AI model; type of pile data and number of dataset; considered soil type; selected effective parameters; estimated output; selected error criteria and measured error value; and applied comparison method. The purpose of providing the list of applied comparison methods for each application is to demonstrate the effectiveness of these techniques compared to other traditional methods.

Load carrying capacity is often the governing factor in the design of pile foundations. This criterion has been examined by several AI researchers especially using ANNs. Table 1 summarizes the input and output parameters used for ANN in previous research.

Table 2 summarizes the outcome of different applications of ANN reviewed in this paper. Overall, 25 different applications have been reviewed and the results are investigated. 


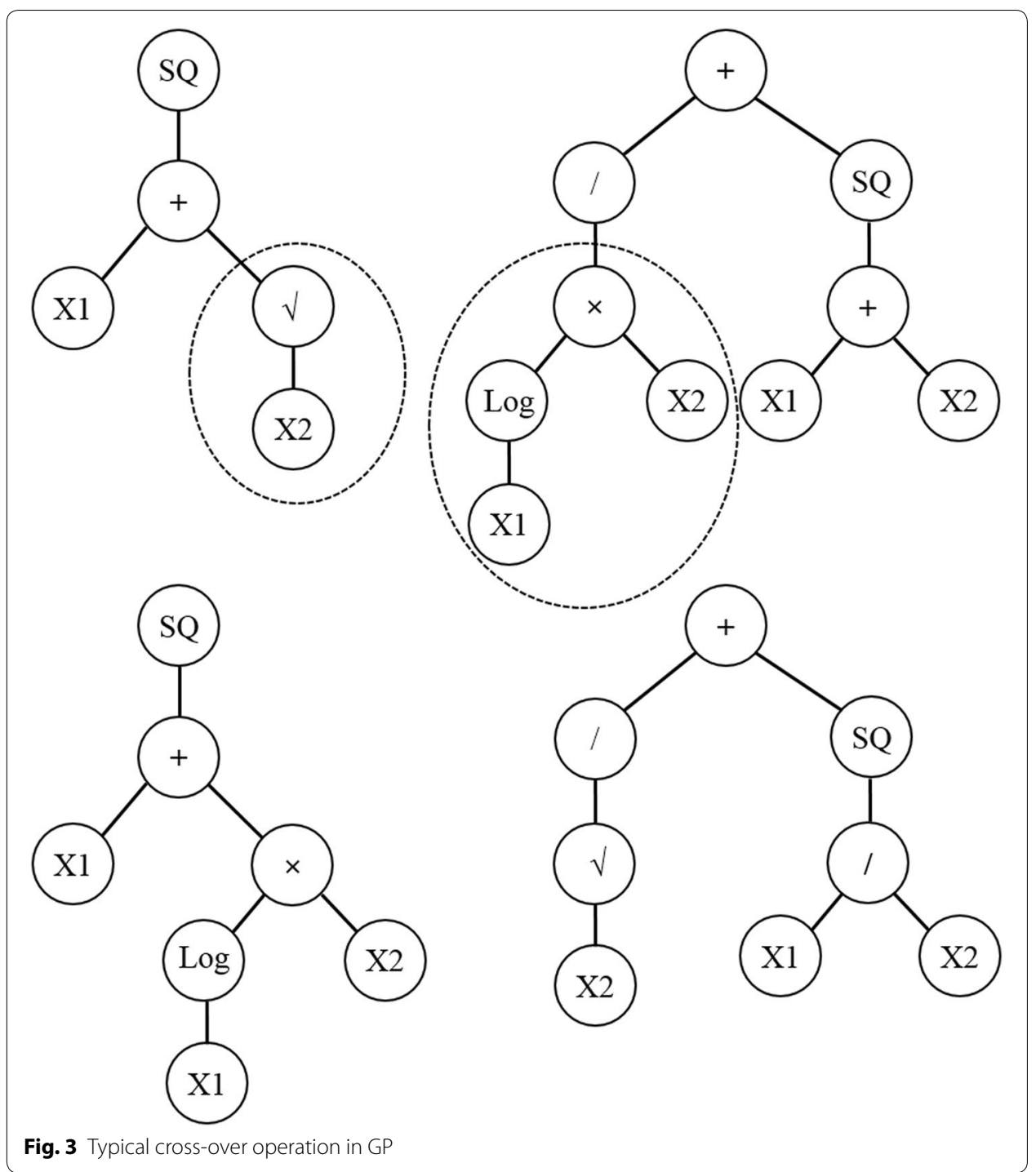

The parameters that were studied for comparison of different applications include: type of ANN model, characteristics of dataset, soil type, input and output variables, error criteria used for validation with respective error value, and selected method of comparison.

Compared to ANN, the application of GP technique for estimating the capacity of pile foundations is relatively new. However, the popularity of GP shows an increased tendency in adopting this technique in estimating the capacity of pile foundations. Table 3 summarizes the input and output parameters used for GP in previous research reviewed in this paper.

Seven applications of GP in estimating the capacity of pile foundations are reviewed in this paper and similar to the trend applied in previous section, the following parameters of each application were analyzed for comparison purpose: type of GP model, characteristics of dataset, soil type, input and output variables, error criteria used for validation 


\section{Table 1 ANN input and output variables}

\begin{tabular}{|c|c|}
\hline Variables & Symbol \\
\hline \multicolumn{2}{|l|}{ Input variables } \\
\hline Pile length & L \\
\hline Pile cross sectional area & A \\
\hline Pile diameter & $\mathrm{D}$ \\
\hline Pile set & $S$ \\
\hline Pile weight & $W_{p}$ \\
\hline Pile modulus of elasticity & $E_{p}$ \\
\hline Type of pile & $T_{p}$ \\
\hline The amount of steel reinforcement & $A_{s}$ \\
\hline Pile circumference & M \\
\hline Pile compression stress & $\sigma_{c}$ \\
\hline Pile tension stress & $\sigma_{t}$ \\
\hline Pile initial axial capacity & $P$ \\
\hline Pile-soil interface friction angle & $\delta$ \\
\hline Elastic compression of the pile and the soil & k \\
\hline Elapsed time after driving & $\mathrm{T}$ \\
\hline Time history of pile head force & $F(t)$ \\
\hline Time history of pile head particle velocity & $V(t)$ \\
\hline Eccentricity of load & $E_{c}$ \\
\hline Hammer weight & $W_{h}$ \\
\hline Hammer drop height & $H_{h}$ \\
\hline Driving energy delivered to the pile & $E$ \\
\hline Average standard penetration number along the pile shaft & SPT-N $_{S}$ \\
\hline Hammer type & $H_{t}$ \\
\hline Number of blows & $\mathrm{N}$ \\
\hline Average standard penetration number along the pile tip & $\mathrm{SPT}_{\mathrm{N}}$ \\
\hline Effective cone point resistance along pile shaft & $q_{E-S}$ \\
\hline Cone sleeve friction along pile shaft & $f_{S-S}$ \\
\hline Effective overburden stress & $\sigma_{v}$ \\
\hline Shear resistance of the soil surrounding the pile shaft & $\mathrm{S}_{\mathrm{s}}$ \\
\hline Soil type around the pile shaft & $\mathrm{T}_{\mathrm{s}}$ \\
\hline Undrained shear strength & $\mathrm{S}_{\mathrm{u}}$ \\
\hline Shear resistance of the soil at the pile tip of the pile & $\mathrm{S}_{b}$ \\
\hline Soil friction angle & $\varphi$ \\
\hline Soil elastic module & $E_{s}$ \\
\hline Soil type around the pile tip & $T_{b}$ \\
\hline Soil consolidation coefficient & $C_{c}$ \\
\hline Drained cohesion of the soil & $C_{d}$ \\
\hline Effective soil specific weight & $\gamma_{e}$ \\
\hline \multicolumn{2}{|l|}{ Output variables } \\
\hline Ultimate load capacity & $\mathrm{P}_{\mathrm{u}}$ \\
\hline Skin friction resistance & $\mathrm{q}_{\mathrm{s}}$ \\
\hline Pile tip capacity & $\mathrm{q}_{\mathrm{b}}$ \\
\hline Undrained side resistance alpha factor for drilled shafts & a \\
\hline Lateral load capacity & $P_{t}$ \\
\hline Undrained lateral load pile capacity & $P_{t-u}$ \\
\hline Pile capacity increase due to setup & $\Delta P$ \\
\hline Time-dependent vertical ultimate bearing capacity & $P_{u}(T)$ \\
\hline
\end{tabular}




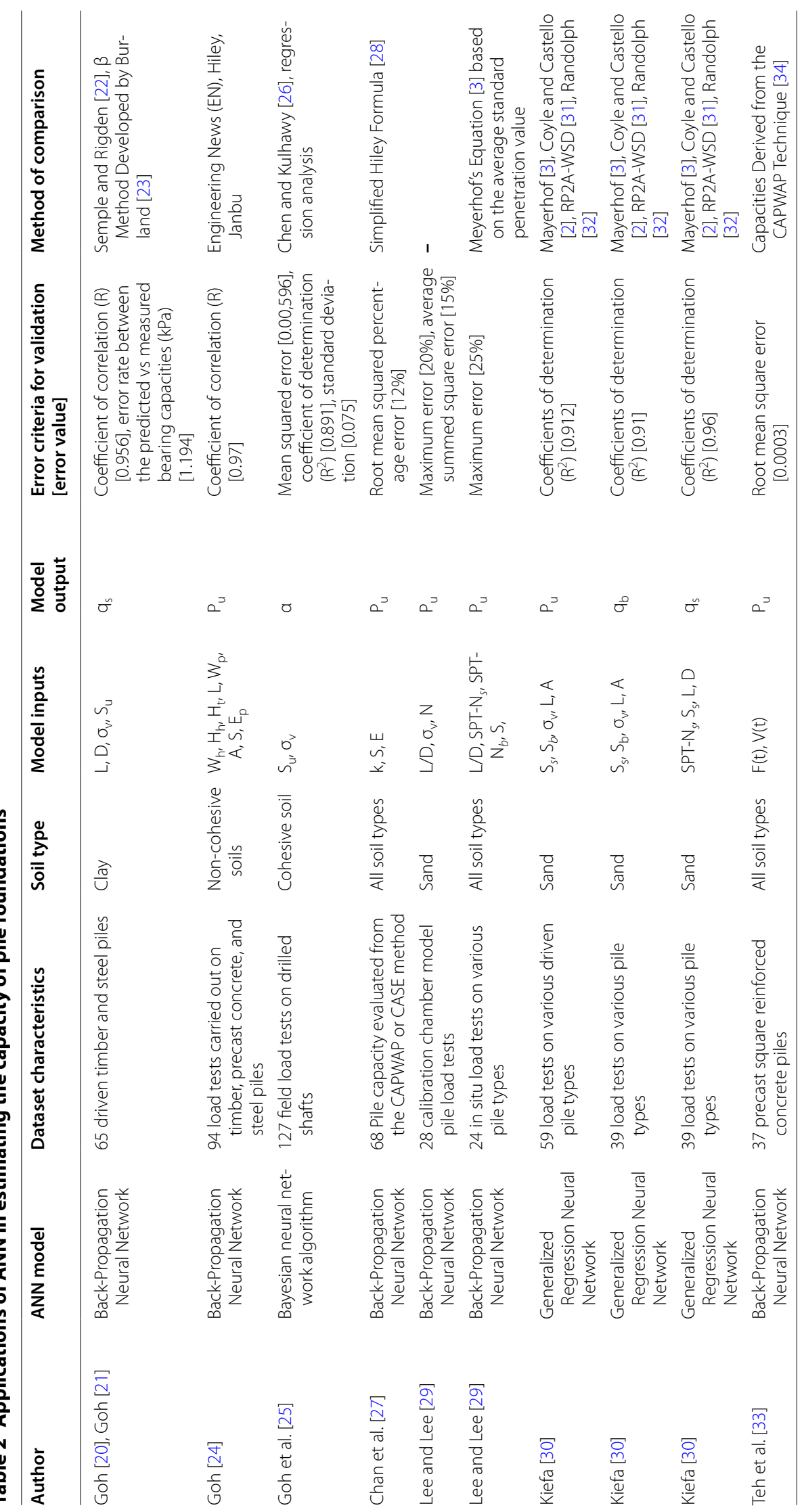




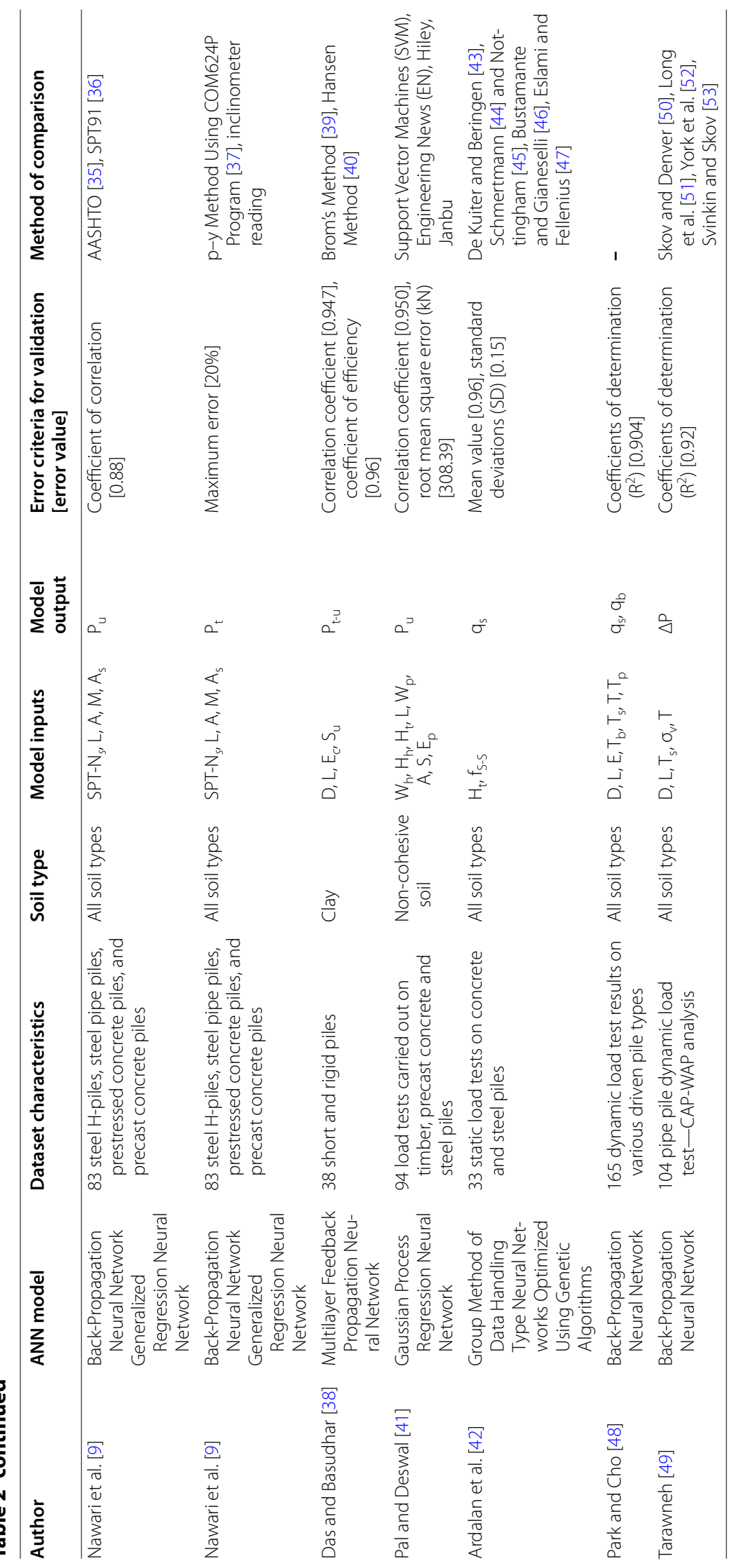




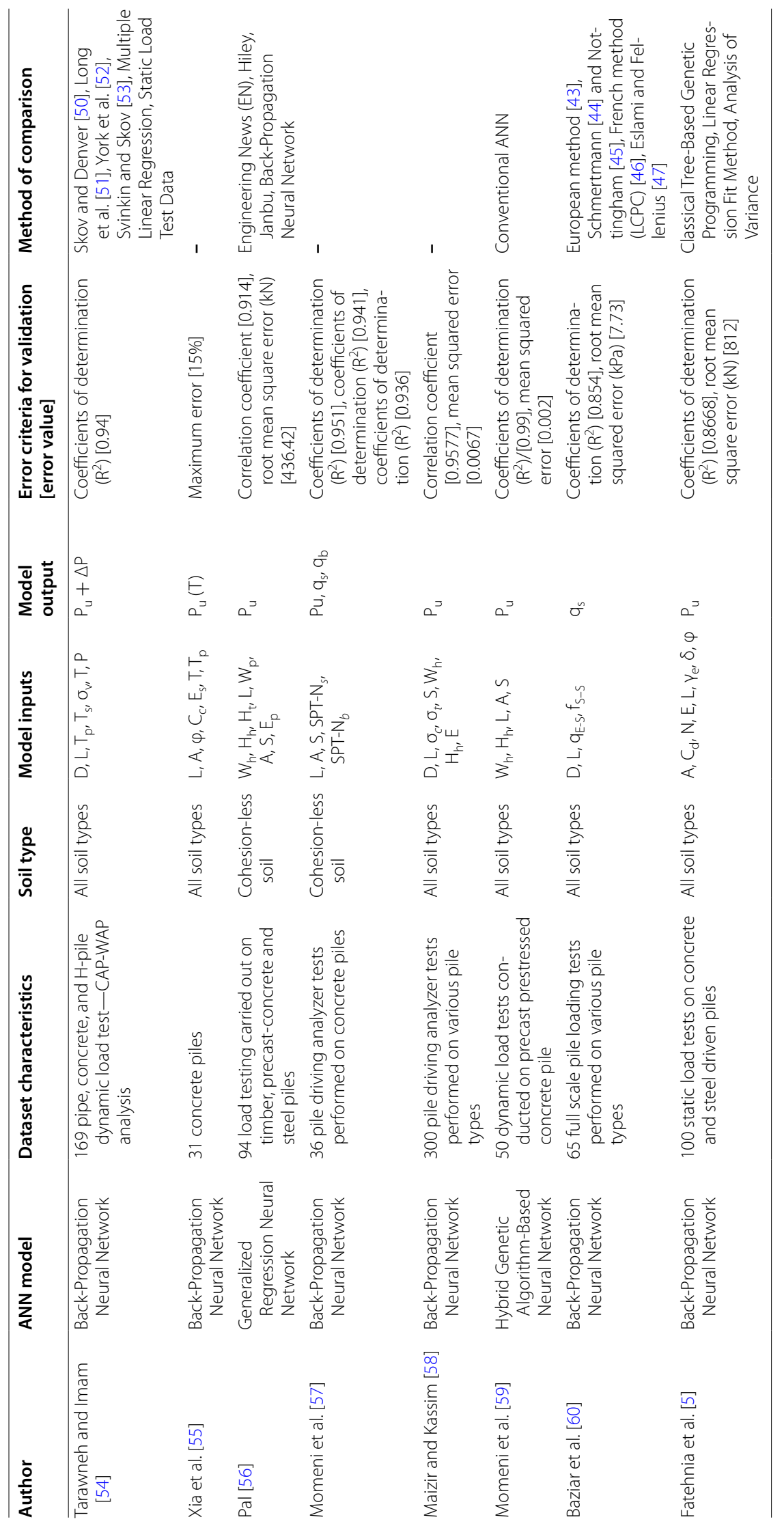


Table 3 GP input and output variables

\begin{tabular}{ll}
\hline Variable & Symbol \\
\hline Input variable & \\
Pile length & $\mathrm{L}$ \\
Pile diameter & $\mathrm{D}$ \\
Pile set & $\mathrm{E}_{\mathrm{p}}$ \\
Pile modulus of elasticity & $\mathrm{T}_{\mathrm{p}}$ \\
Type of pile & $\mathrm{E}$ \\
Driving energy delivered to the pile & $\mathrm{SPT}-\mathrm{N}_{\mathrm{S}}$ \\
Average standard penetration number along the pile shaft & $\mathrm{SPT}-\mathrm{N}_{b}$ \\
Average standard penetration number along the pile tip & $\mathrm{q}_{\mathrm{E}-\mathrm{T}}$ \\
Cone point resistance at pile tip & $\mathrm{f}_{\mathrm{S}-\mathrm{S}}$ \\
Cone sleeve friction along pile shaft & $\mathrm{q}_{\mathrm{E}-\mathrm{S}}$ \\
Cone point resistance along pile shaft & $\mathrm{D}_{\mathrm{fh}}$ \\
Lateral force point of application distance & $\mathrm{F}_{\mathrm{t}}$ \\
Chain force angle with the horizontal & $\mathrm{R}_{\mathrm{f}}$ \\
Loading rate & $\mathrm{e}_{\mathrm{f}}$ \\
Eccentricity of load & $\sigma_{\mathrm{v}}$ \\
Effective overburden stress & $\mathrm{S}_{\mathrm{U}-\mathrm{T}}$ \\
Undrained shear strength at pile tip & $\mathrm{k}$ \\
Permeability of the soil & \\
Output variables & $\mathrm{P}_{\mathrm{u}}$ \\
Ultimate load capacity & $\mathrm{P}_{\mathrm{U}-\mathrm{S}}$ \\
Ultimate capacity of suction caisson & $\mathrm{P}_{\mathrm{UC}-\mathrm{S}}$ \\
Uplift capacity of suction caissons & $\mathrm{P}_{\mathrm{lu}}$ \\
Undrained lateral load capacity & $\mathrm{a}$ \\
Undrained side resistance alpha factor & \\
\hline
\end{tabular}

with respective error value, and selected method of comparison. Table 4 shows this information for the seven analyzed applications.

\section{Discussion}

In order to better understand the different applications of AI techniques in pile capacity estimation, a statistical analysis was conducted on the input and output variables of the analyzed applications. This is useful in realizing the importance of different variables and their effects on pile capacities in previous research. It will also show which type of variables had the highest importance in previous applications and will help in selecting the proper variables for future research.

\section{Artificial Neural Networks}

The input variables adopted in the previous ANN research that are analyzed in this paper can be categorized into 4 main subdivisions. These subdivisions include pile properties, loading history, hammer/SPT/CPT information, and soil properties. Overall, in all 25 studied applications, 38 different input variables were adopted. Table 5 shows the adopted input variables categorized into 4 main groups, and their repeat numbers in all 25 analyzed ANN applications. Pile length was the most adopted variable with 21 repeat 


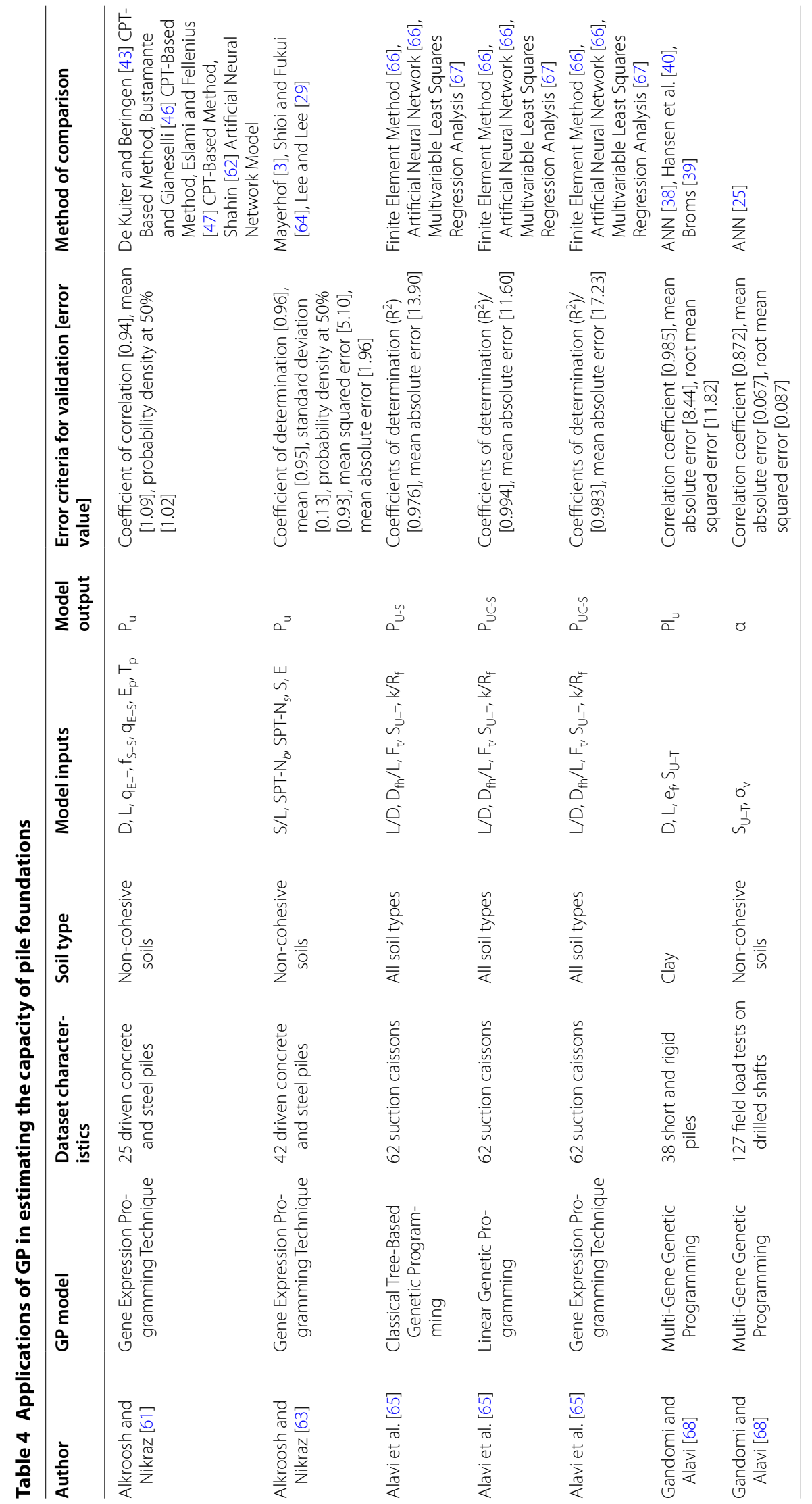


Table 5 ANN input variables

\begin{tabular}{|c|c|c|}
\hline Input variable & Symbol & Repeat number \\
\hline \multicolumn{3}{|l|}{ Pile properties } \\
\hline Pile length & $\mathrm{L}$ & 21 \\
\hline Pile cross sectional area & A & 11 \\
\hline Pile diameter & $\mathrm{D}$ & 10 \\
\hline Pile set & $\mathrm{S}$ & 8 \\
\hline Pile weight & $W_{p}$ & 3 \\
\hline Pile modulus of elasticity & $E_{p}$ & 3 \\
\hline Type of pile & $T_{p}$ & 3 \\
\hline The amount of steel reinforcement & $A_{s}$ & 2 \\
\hline Pile circumference & M & 2 \\
\hline Pile compression stress & $\sigma_{c}$ & 1 \\
\hline Pile tension stress & $\sigma_{t}$ & 1 \\
\hline Pile initial axial capacity & $P$ & 1 \\
\hline Pile-soil interface friction angle & $\delta$ & 1 \\
\hline Elastic compression of the pile and the soil & k & 1 \\
\hline \multicolumn{3}{|l|}{ Loading history } \\
\hline Elapsed time after driving & $\mathrm{T}$ & 4 \\
\hline Time history of pile head force & $F(t)$ & 1 \\
\hline Time history of pile head particle velocity & $V(t)$ & 1 \\
\hline Eccentricity of load & $E_{c}$ & 1 \\
\hline \multicolumn{3}{|l|}{ Hammer/SPT/CPT information } \\
\hline Hammer weight & $W_{h}$ & 5 \\
\hline Hammer drop height & $H_{h}$ & 5 \\
\hline Driving energy delivered to the pile & $\mathrm{E}$ & 5 \\
\hline Average standard penetration number along the pile shaft & $\mathrm{SPT}^{-N_{s}}$ & 5 \\
\hline Hammer type & $H_{t}$ & 3 \\
\hline Number of blows & $\mathrm{N}$ & 2 \\
\hline Average standard penetration number along the pile tip & $\mathrm{SPT}_{\mathrm{N}} \mathrm{N}_{b}$ & 2 \\
\hline Effective cone point resistance along pile shaft & $q_{E-S}$ & 2 \\
\hline Cone sleeve friction along pile shaft & $f_{S-S}$ & 2 \\
\hline \multicolumn{3}{|l|}{ Soil properties } \\
\hline Effective overburden stress & $\sigma_{v}$ & 7 \\
\hline Shear resistance of the soil surrounding the pile shaft & $\mathrm{S}_{\mathrm{s}}$ & 3 \\
\hline Soil type around the pile shaft & $T_{s}$ & 3 \\
\hline Undrained shear strength & $\mathrm{S}_{\mathrm{u}}$ & 3 \\
\hline Shear resistance of the soil at the pile tip of the pile & $S_{b}$ & 2 \\
\hline Soil friction angle & $\varphi$ & 2 \\
\hline Soil elastic module & $E_{s}$ & 1 \\
\hline Soil type around the pile tip & $T_{b}$ & 1 \\
\hline Soil consolidation coefficient & $C_{c}$ & 1 \\
\hline Drained cohesion of the soil & $C_{d}$ & 1 \\
\hline Effective soil specific weight & $\gamma_{e}$ & 1 \\
\hline
\end{tabular}

among all 25 studied applications. Pile cross sectional area and pile diameter had the highest number of repeat after pile length.

The percentage of repeat for the four categories of ANN input variables is depicted in Fig. 4 where pile properties had the highest percentage of repeat, while, the loading history had the lowest repeat percentage. Hammer/SPT/CPT and soil properties are parameters that are used in slightly less than half of the ANN studies. 


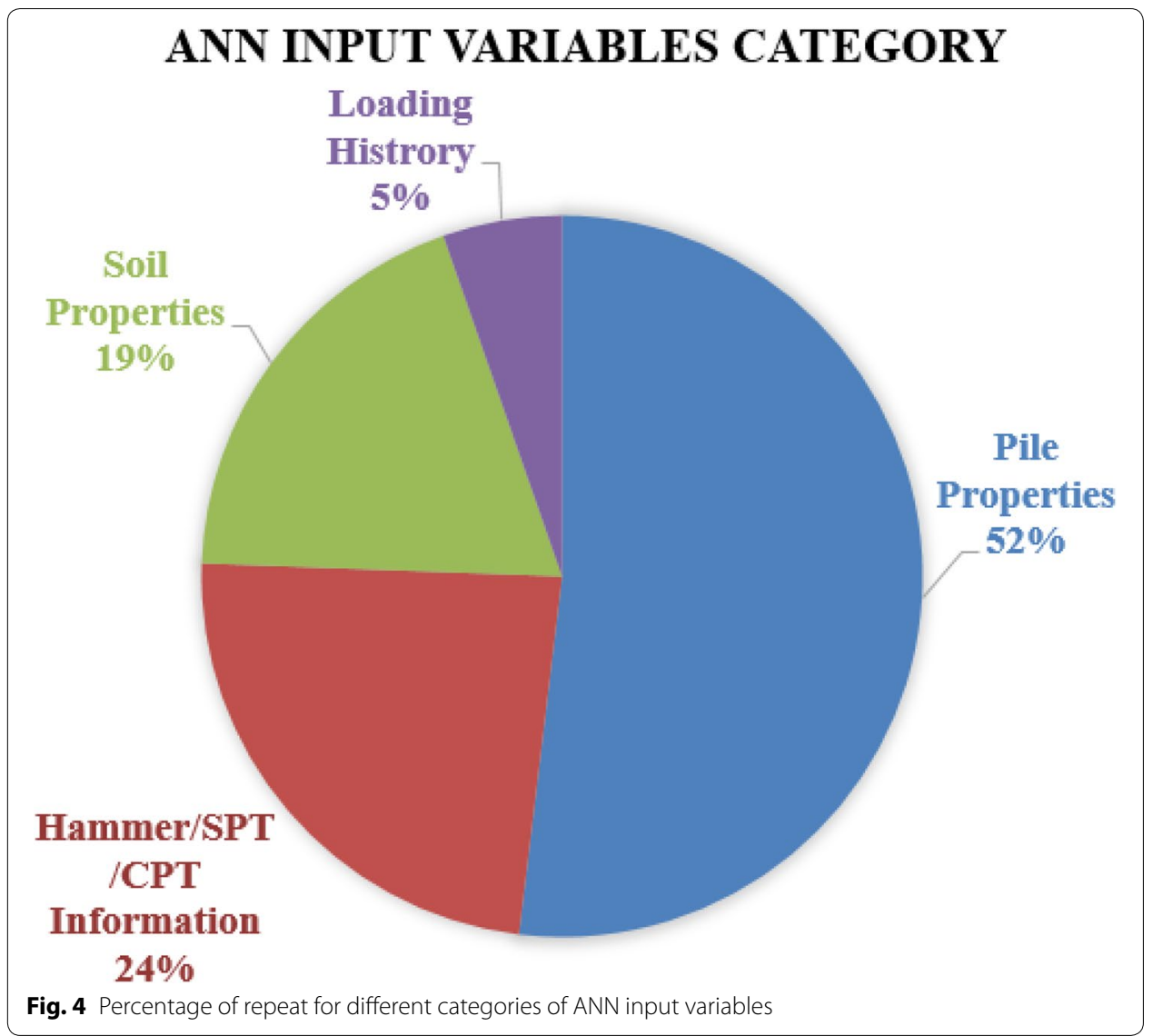

Percentage of repeat of input variables in each category of ANN applications is shown in Fig. 5. The information in Fig. 5 helps us to see which parameters in each category has had the highest repeat percentage. Figure 5 a shows that, between all parameters related to pile properties, the pile length with $31 \%$ repeat rate, was the most applied variable. Pile cross sectional area and pile diameter with 16 and 15\% usage were following the pile length. For the loading history presented in Fig. 5b, the elapsed time after driving with $57 \%$ contribution, had the highest repeat percentage. In hammer/SPT/CPT information category, hammer weight, hammer drop height, driving energy delivered to the pile, and average SPT Along the pile shaft had similar repeat percentage of $16 \%$ and were the highest applied variables as an input of ANN models (Fig. 5c). In soil properties category (Fig. 5d), the effective overburden stress with $28 \%$ repeat percentage, had the highest repeat rate among previous related studies where shear resistance of the soil surrounding the pile shaft, soil type around the pile shaft, and undrained shear strength has equal usage of $12 \%$ in previous ANN studies on piles.

The variables applied as an output of ANN models together with their repeat numbers in all 25 applications are shown in Table 6 . The ultimate load capacity with 14 number of repeat was the main variables of interest in previous research. Skin friction resistance and pile tip capacity had the highest repeat number after ultimate load capacity. However, both skin friction resistance and pile tip capacity are directly or indirectly used to estimate the ultimate load capacity of pile foundations. 

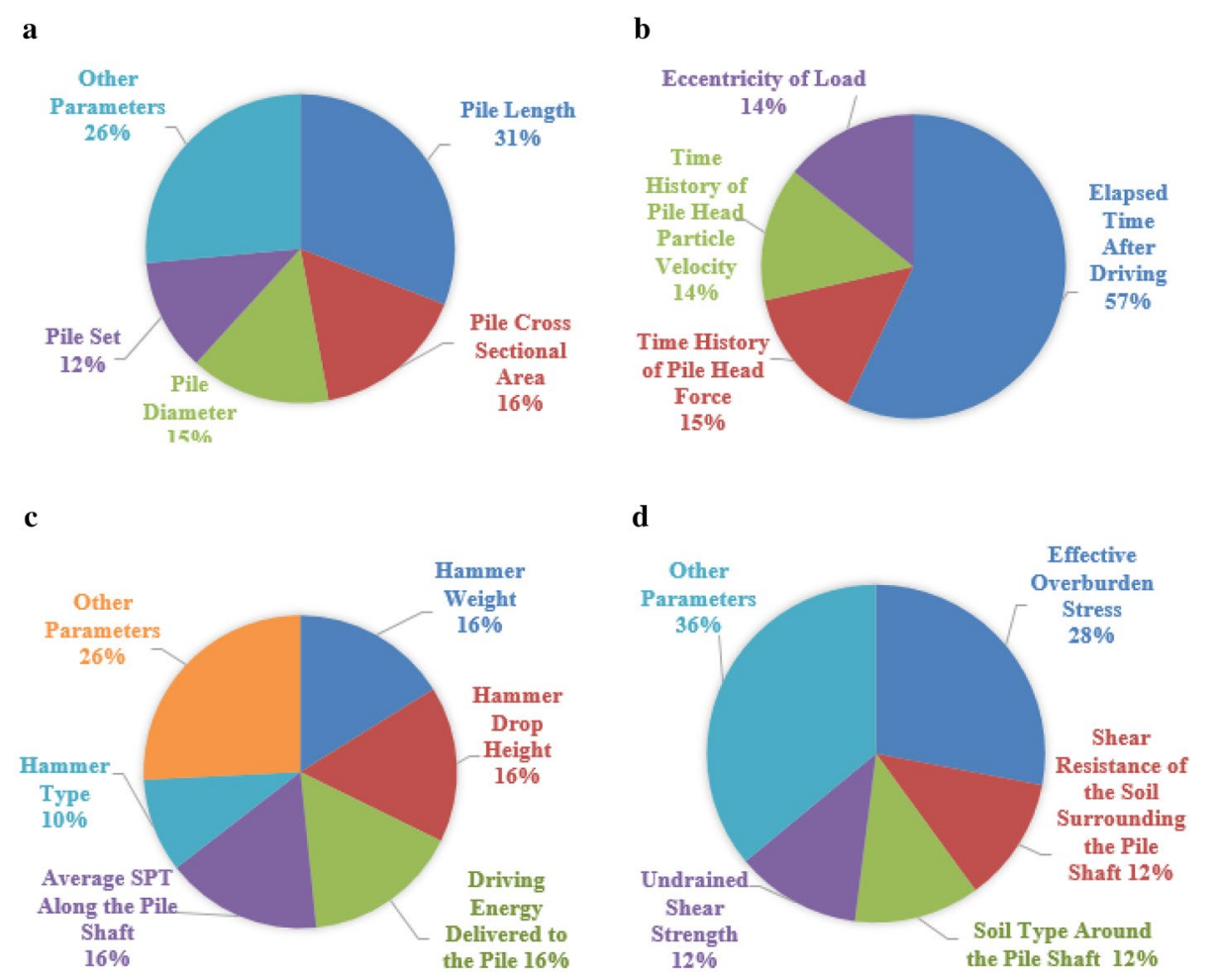

Fig. 5 Percentage of repeat of input variables in ANN applications for (a) pile properties, (b) loading history, (c) hammer/SPT/CPT information, and (d) soil properties

Table 6 ANN estimated variables

\begin{tabular}{lll}
\hline Estimated variable & Symbol & Repeat number \\
\hline Ultimate load capacity & $P_{u}$ & 14 \\
Skin friction resistance & $\mathrm{q}_{\mathrm{s}}$ & 6 \\
Pile tip capacity & $\mathrm{q}_{\mathrm{b}}$ & 3 \\
Undrained side resistance alpha factor for drilled shafts & $\mathrm{a}$ & 1 \\
Lateral load capacity & $\mathrm{P}_{\mathrm{t}}$ & 1 \\
Undrained lateral load pile capacity & $\mathrm{P}_{\mathrm{t}-\mathrm{u}}$ & 1 \\
Pile capacity increase due to setup & $\Delta \mathrm{P}$ & 1 \\
Time-dependent vertical ultimate bearing capacity & $\mathrm{P}_{\mathrm{u}}(\mathrm{T})$ & 1 \\
\hline
\end{tabular}

\section{Genetic Programming}

As discussed before, compared to ANN, GP is a newer technique for intelligence analysis of piles. Hence the number of parameters used in GP in each category are smaller than ANN. Overall, in 7 reviewed studies in this research, 19 different parameters have been used for GP. By following the four classification of the analyzed properties in previous AI studies on piles, Table 7 presents the input variables used for GP. Similar to parameters studied by ANN, pile length and undrained shear strength at pile tip were the most used parameters.

For pile properties category, previous studies only focused on 5 different parameters, where in ANN, 15 different parameters have been investigated. Parameters such as pile 
Table 7 GP input variables

\begin{tabular}{|c|c|c|}
\hline Input variable & Symbol & Repeat number \\
\hline \multicolumn{3}{|l|}{ Pile properties } \\
\hline Pile length & $\mathrm{L}$ & 6 \\
\hline Pile diameter & $\mathrm{D}$ & 5 \\
\hline Pile set & $\mathrm{S}$ & 1 \\
\hline Pile modulus of elasticity & $E_{p}$ & 1 \\
\hline Type of pile & $T_{p}$ & 1 \\
\hline \multicolumn{3}{|l|}{ Hammer/SPT/CPT information } \\
\hline Driving energy delivered to the pile & $\mathrm{E}$ & 1 \\
\hline Average standard penetration number along the pile shaft & $\mathrm{SPT} \mathrm{N}_{S}$ & 1 \\
\hline Average standard penetration number along the pile tip & $\mathrm{SPT}_{\mathrm{N}}$ & 1 \\
\hline Cone point resistance at pile tip & $q_{E-T}$ & 1 \\
\hline Cone sleeve friction along pile shaft & $f_{S-S}$ & 1 \\
\hline Cone point resistance along pile shaft & $q_{E-S}$ & 1 \\
\hline \multicolumn{3}{|l|}{ Loading history } \\
\hline Lateral force point of application distance & $D_{\text {fh }}$ & 3 \\
\hline Chain force angle with the horizontal & $F_{t}$ & 3 \\
\hline Loading rate & $R_{f}$ & 3 \\
\hline Eccentricity of load & $e_{f}$ & 1 \\
\hline \multicolumn{3}{|l|}{ Soil properties } \\
\hline Effective overburden stress & $\sigma_{v}$ & 1 \\
\hline Undrained shear strength at pile tip & $\mathrm{S}_{U-T}$ & 5 \\
\hline Permeability of the soil & k & 3 \\
\hline
\end{tabular}

weight $\left(\mathrm{W}_{\mathrm{p}}\right)$, amount of steel reinforcement $\left(\mathrm{A}_{\mathrm{s}}\right)$, pile circumference $(\mathrm{M})$, pile initial axial capacity $(\mathrm{P})$, and pile-soil interface friction angle $(\delta)$ has not been investigated by GP. For hammer SPT/CPT information, ANN covered 9 parameters where GP only have covered 6 parameters. Hammer drop height $\left(\mathrm{H}_{\mathrm{h}}\right)$, number of blows $(\mathrm{N})$, and hammer weight $\left(\mathrm{W}_{\mathrm{h}}\right)$ are parameters that are investigated in ANN but not covered by GP in previous studies. In soil properties, ANN was more developed where 11 parameters have been investigated in the literature; however, only three parameters have been used for GP. Hence, parameters such as effective soil specific weight $\left(\gamma_{\mathrm{e}}\right)$, soil friction angle $(\phi)$, soil type around the pile shaft $\left(\mathrm{T}_{\mathrm{s}}\right)$, and etc. can be used in future GP studies on piles. In loading history category, GP used different load parameters than ANN.

The percentage of repeat for the four categories of GP input variables is illustrated in Fig. 6. Similar to ANN, pile properties had the highest percentage of repeat; however, the percentage of using pile properties in ANN (52\%) was 16\% larger than its usage in GP (36\%). Opposite to ANN, loading history plays an important role for adopted parameters in GP with $23 \%$ where for ANN, it only contributed by $5 \%$. Soil properties for both ANN and GP has high percentage of usage; however, it was used in GP slightly more than ANN (by 7\%). Hammer/SPT/CPT for GP has usage percentage of $15 \%$ where in ANN it has a contribution of $24 \%$ in the previous studies.

Percentage of repeat of input variables in each category of GP applications is shown in Fig. 7. Figure 7a shows that, between all parameters related to pile properties, the pile length with $43 \%$ repeat rate, was the most applied variable. Pile diameter with $36 \%$ was the second frequent used parameter. For the loading history presented in Fig. $7 \mathrm{~b}$, the 


\section{GP INPUT VARIABLES \\ CATEGORY}

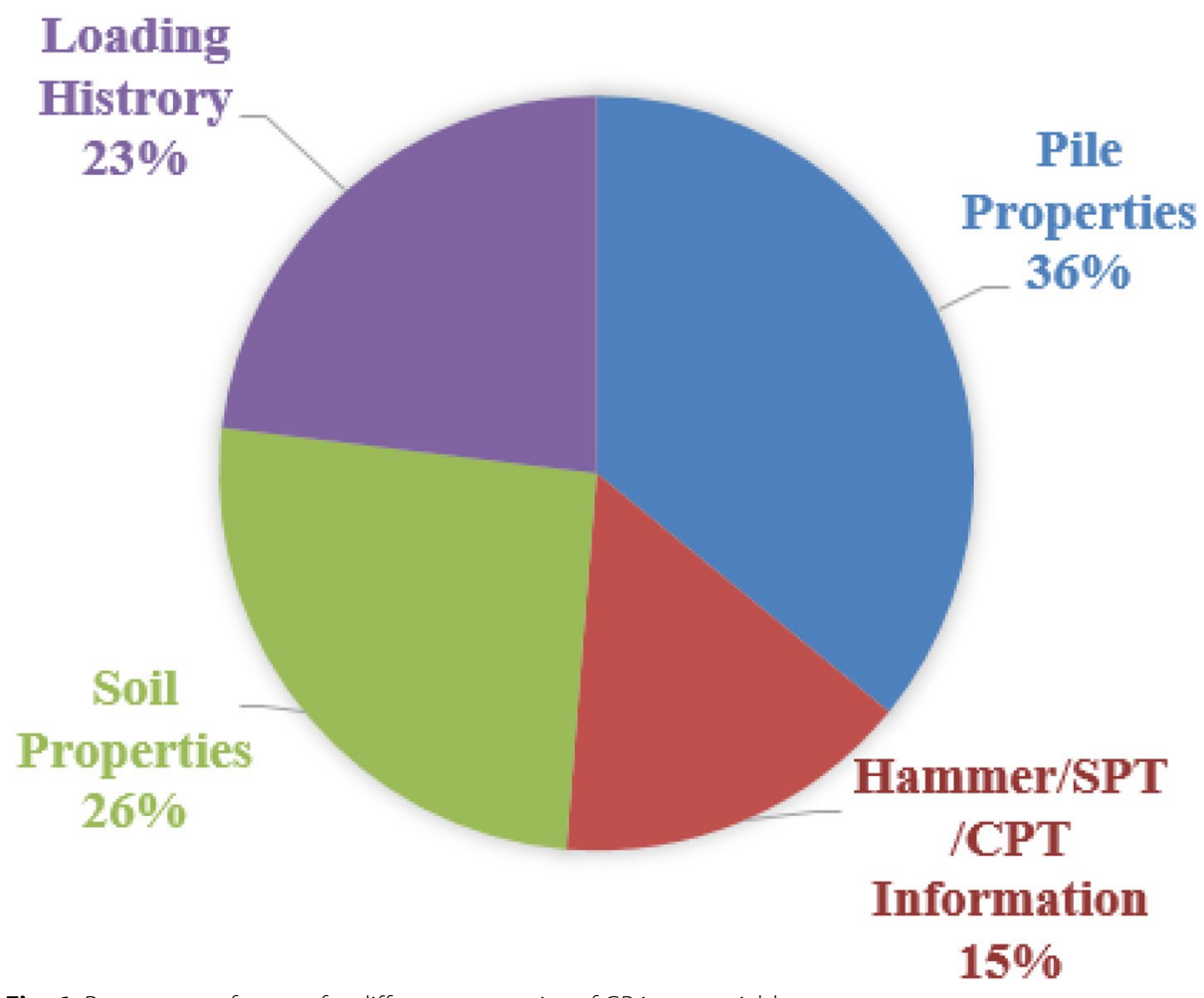

Fig. 6 Percentage of repeat for different categories of GP input variables

lateral force point of application, chain force angle with the horizontal, and loading rate had equal contribution of $30 \%$. In hammer/SPT/CPT information category, all parameters had equal usage percentage in previous studies (Fig. 7d). In soil properties category (Fig. 7d), undrained shear strength at pile tip with 56\% usage was the most frequent used parameter.

Table 8 summarizes the output variables of GP models with their repeat numbers in all reviewed cases. Similar to ANN, The ultimate load capacity is the most interested parameter resulted from GP. The uplift capacity of suction caissons is another parameter considered in GP; however, it was not interested in ANN studies. Other parameters such as ultimate capacity of suction caissons, undrained lateral load capacity, and undrained side resistance alpha factor were also considered in GP. The comparison of the output parameters in ANN and GP showed that uplift capacity of suction caissons and ultimate capacity of suction caissons were only considered in GP.

\section{Conclusions}

In this review paper, initially the importance of AI in geotechnical engineering was discussed. Subsequently, the two well-known AI techniques of ANN and GP were introduced. Afterward, a detailed review of the previous studies on pile foundations was conducted and a list of applied variables as well as their usage frequencies were 


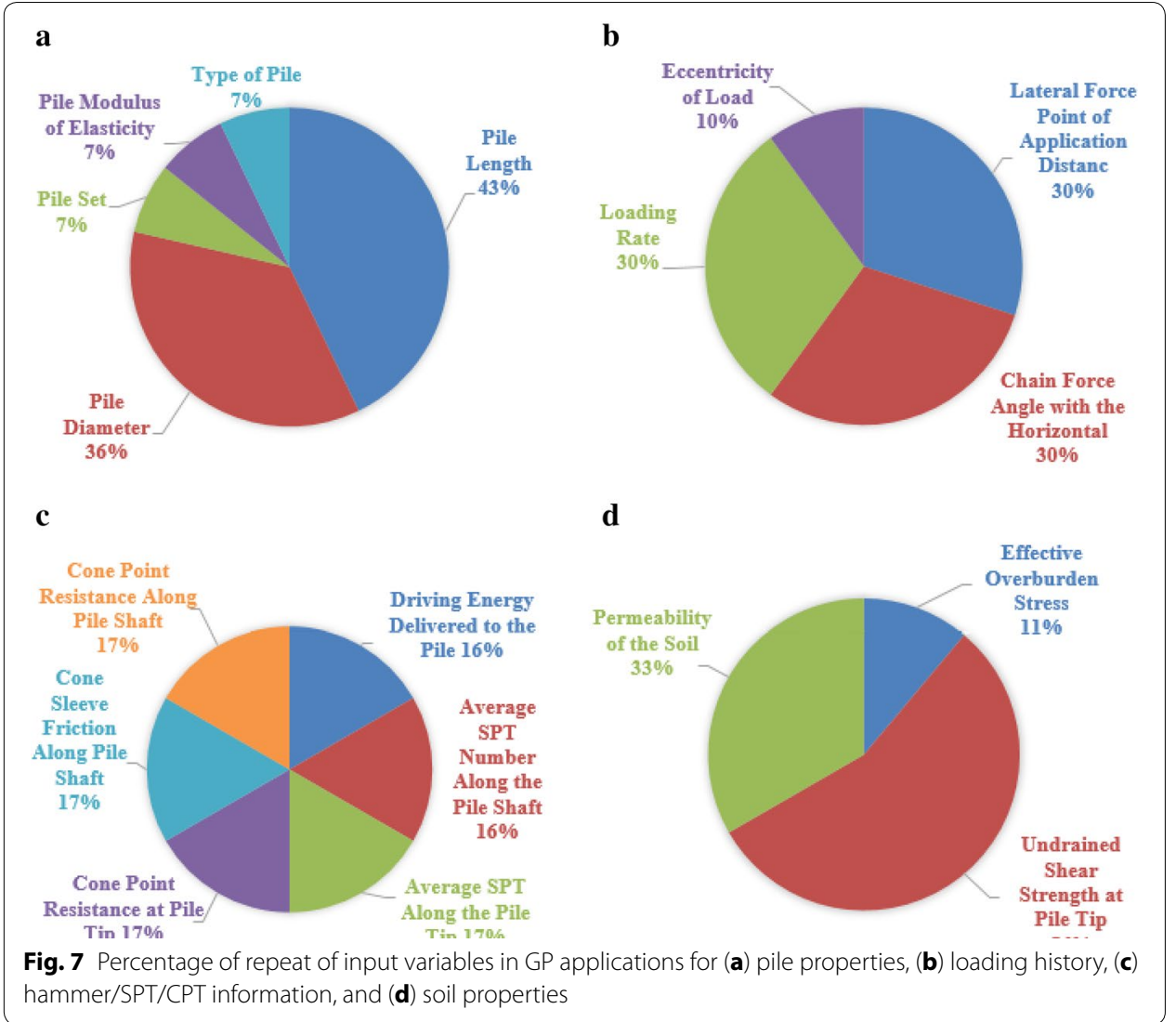

Table 8 GP estimated variables

\begin{tabular}{lll}
\hline Estimated variable & Symbol & Repeat number \\
\hline Ultimate load capacity & $P_{\mathrm{u}}$ & 2 \\
Uplift capacity of suction caissons & $\mathrm{P}_{\mathrm{UC}-\mathrm{S}}$ & 2 \\
Ultimate capacity of suction caisson & $\mathrm{P}_{\mathrm{U}-\mathrm{S}}$ & 1 \\
Undrained lateral load capacity & $\mathrm{P}_{\mathrm{lu}}$ & 1 \\
Undrained side resistance alpha factor & $a$ & 1 \\
\hline
\end{tabular}

presented. Results of this paper will help in better understanding the importance of different variables and their effects on pile capacities in previous research. In addition, it will help in choosing other important or un-investigated parameters for future research. Based on the reviewed articles and used parameters, the followings were concluded:

- Overall, in all 25 studied ANN applications, 38 different input variables were adopted. Pile length was the most adopted variable with 21 repeat among all variables. Pile cross sectional area and pile diameter had the highest number of repeat after pile length. Among all four main categories of variables, pile properties had the highest percentage of repeat, while, the loading history had the lowest repeat percentage. Hammer/SPT/CPT and soil properties were used in slightly less than half of the ANN studies. 
- Compared to ANN, GP is a newer technique for artificial intelligence analysis of pile capacity. Among GP applications, pile length, pile diameter, and undrained shear strength at pile tip were the most applied variables. Similar to ANN, among the four main categories of variables, pile properties had the highest percentage of repeat; however, the percentage of using pile properties in ANN (52\%) was 16\% larger than its usage in GP (36\%). Specifically, for pile properties category, GP studies were only focused on 5 different variables, whereas in ANN, 14 different variables have been investigated. Parameters such as pile weight $\left(\mathrm{W}_{\mathrm{p}}\right)$, amount of steel reinforcement $\left(A_{s}\right)$, pile circumference $(M)$, pile initial axial capacity $(P)$, and pile-soil interface friction angle $(\delta)$ have not been investigated by GP. Overall, in the seven reviewed GP applications, only 18 different variables have been applied. Comparing this number with 38 applied variables in ANN applications shows that further studies are needed to explore more variables in GP.

- The ultimate load capacity was the most evaluated output parameter among both ANN and GP. The uplift capacity of suction caissons was another variable considered in GP; however, it was not evaluated in ANN studies. The comparison of the output variables in ANN and GP showed that uplift capacity of suction caissons and ultimate capacity of suction caissons were only considered in GP. Hence, future ANN studies may consider these variables for characterization of soil-pile interactions.

Authors' contributions

GA performed the analysis of the data. MF drafted the manuscript. Both authors read and approved the final manuscript.

Author details

${ }^{1}$ Department of Civil and Environmental Engineering, Florida A\&M University-Florida State University College of Engineering, Tallahassee, FL 32310, USA. ${ }^{2}$ ECS Southeast, LLP, Marietta, GA 30066, USA.

Competing interests

The authors declare that they have no competing interests.

Ethics approval and consent to participate

Not applicable.

\section{Publisher's Note}

Springer Nature remains neutral with regard to jurisdictional claims in published maps and institutional affiliations.

Received: 6 April 2017 Accepted: 7 December 2017

Published online: 09 January 2018

\section{References}

1. Amirinia G, Jung S (2017) Buffeting response analysis of offshore wind turbines subjected to hurricanes. Ocean Eng 141:1-11

2. Coyle HM, Castello RR (1981) New design correlations for piles in sand. J Geotech Geoenviron Eng 107:965-985

3. Mayerhof G (1976) Bearing capacity and settlemtn of pile foundations. J Geotech Geoenviron Eng 102:195-228

4. Fatehnia M, Paran S, Kish S, Tawfiq K (2016) Automating double ring infiltrometer with an Arduino microcontroller. Geoderma 262:133-139

5. Fatehnia M, Tawfiq K, Hataf N, Ozguven EE (2015) New method for predicting the ultimate bearing capacity of driven piles by using Flap number. KSCE J Civ Eng 19:611-620

6. Fatehnia M, Tawfiq K, Ye M (2016) Estimation of saturated hydraulic conductivity from double-ring infiltrometer measurements. Eur J Soil Sci 67:135-147

7. Mafi S, Amirinia G (2017) Forecasting hurricane wave height in Gulf of Mexico using soft computing methods. Ocean Eng 146:352-362

8. Mafi S, Yeganeh-Bakhtiary A, Kazeminezhad MH (2013) Prediction formula for longshore sediment transport rate with M5'algorithm. J Coastal Res 65:2149-2154

9. Nawari N, Liang R, Nusairat J (1999) Artificial intelligence techniques for the design and analysis of deep foundations. Electron J Geotech Eng 4:1-21

10. Fatehnia M, Tawfiq K, Abichou T (2014) Comparison of the methods of hydraulic conductivity estimation from mini disk infiltrometer. EJGE. 19:1047-1063 
11. Paran S (2016) Distributed model predictive control based intelligent energy management for AC microgrids. The Florida State University, Tallahassee

12. Gardner MW, Dorling S (1998) Artificial neural networks (the multilayer perceptron) - a review of applications in the atmospheric sciences. Atmospheric Environ 32:2627-2636

13. McCulloch WS, Pitts W (1943) A logical calculus of the ideas immanent in nervous activity. Bull Math Biophys 5:115-133

14. Bendana R, del Cano A, Pilar de la Cruz M (2008) Contractor selection: fuzzy-control approach. Canadian J Civil Eng 35:473-486

15. Banimahd M, Yasrobi S, Woodward P (2005) Artificial neural network for stress-strain behavior of sandy soils: knowledge based verification. Comput Geotech 32:377-386

16. Caglar N, Arman H (2007) The applicability of neural networks in the determination of soil profiles. Bull Eng Geol Env 66:295-301

17. Shahin MA, Jaksa MB, Maier HR (2009) Recent advances and future challenges for artificial neural systems in geotechnical engineering applications. Adv Artif Neural Syst 2009:5

18. Koza JR (1992) Genetic programming: on the programming of computers by means of natural selection. MIT press, Massachusetts

19. Sette S, Boullart L (2001) Genetic programming: principles and applications. Eng Appl Artif Intell 14:727-736

20. Goh A (1994) Nonlinear modelling in geotechnical engineering using neural networks. Trans Inst Eng Aust Civil Eng 36:293-297

21. Goh A (1995) Back-propagation neural networks for modeling complex systems. Artif Intell Eng 9:143-151

22. Semple RM, Rigden WJ (1984) Shaft capacity of driven pipe piles in clay. Analysis and design of pile foundations. ASCE, Reston, pp 59-79

23. Burland J (1973) Shaft friction of piles in clay - a simple fundamental approach. Ground Engineering, London, p 6

24. Goh A (1995) Empirical design in geotechnics using neural networks. Geotechnique 45:709-714

25. Goh AT, Kulhawy FH, Chua C (2005) Bayesian neural network analysis of undrained side resistance of drilled shafts. J Geotech Geoenviron Eng 131:84-93

26. Chen Y, Kulhawy F (1994) Case history evaluation of the behaviour of drilled shafts under axial and lateral loading. Final report, Project 1493-04. EPRI TR-104601, Geotechnical Group, Cornell University, Ithaca

27. Chan W, Chow Y, Liu L (1995) Neural network: an alternative to pile driving formulas. Comput Geotech 17:135-156

28. Broms B, Lim P (1988) A simple pile driving formula based on stress-wave measurements. In: Proceedings, the 3rd international conference on the application of stress-wave theory to piles: Vancouver, pp 591-600

29. Lee I-M, Lee J-H (1996) Prediction of pile bearing capacity using artificial neural networks. Comput Geotech 18:189-200

30. Kiefa MA (1998) General regression neural networks for driven piles in cohesionless soils. J Geotech Geoenviron Eng 124:1177-1185

31. RP2A-WSD A (2000) Recommended practice for planning, designing and constructing fixed offshore platformsworking stress design. Twenty

32. Randolph MF (1985) Capacity of piles driven into dense sand. University of Cambridge, Engineering Department, Cambridge

33. Teh C, Wong K, Goh A, Jaritngam S (1997) Prediction of pile capacity using neural networks. J Comput Civil Eng 11:129-138

34. Rausch F, Moses F, Goble GG (1972) Soil resistance predictions from pile dynamics. J Soil Mech Found Division 98:917-937

35. Aashto L (1998) LRFD bridge design specifications. American Association of State Highway and Transportation Officials, Washington

36. Caliendo J, Bartholomew M, Lai P, Towsend F, McVay M (1994) Static pile capacity prediction with SPT91. In: Proceedings international conference On Design and Construction of Deep Foundations. Orlando, US Federal Highway Administration, vol 2, pp 724-737

37. Wang S-T, Reese LC (1993) COM624P: laterally loaded pile analysis program for the microcomputer, Version 2.0: US Department of Transportation, Federal Highway Administration, Office of Technology Applications

38. Das SK, Basudhar PK (2006) Undrained lateral load capacity of piles in clay using artificial neural network. Comput Geotech 33:454-459

39. Broms BB (1964) Lateral resistance of piles in cohesive soils. J Soil Mech Found Div 90:27-64

40. Hansen JB, Brinch-Hansen J, Hansen JB (1961) The ultimate resistance of rigid piles against transversal forces. The Danish Geotechnical Institute, Copenhagen

41. Pal M, Deswal S (2010) Modelling pile capacity using Gaussian process regression. Comput Geotech 37:942-947

42. Ardalan H, Eslami A, Nariman-Zadeh N (2009) Piles shaft capacity from CPT and CPTu data by polynomial neural networks and genetic algorithms. Comput Geotech 36:616-625

43. De Kuiter J, Beringen F (1979) Pile foundations for large North Sea structures. Mar Georesour Geotechnol 3:267-314

44. Schmertmann JH (1978) Guidelines for cone penetration test (performance and design)

45. Nottingham LC (1975) Use of quasi-static friction cone penetrometer data. To predict load capacity of displacement piles. University of Florida, Gainesville

46. Bustamante M, Gianeselli L (1982) Pile bearing capacity prediction by means of static penetrometer CPT. In: Proceedings of the 2-nd European symposium on penetration testing, pp 493-500

47. Eslami A, Fellenius BH (1997) Pile capacity by direct CPT and CPTu methods applied to 102 case histories. Can Geotech J 34:886-904

48. Park H, Cho C (2010) Neural network model for predicting the resistance of driven piles. Mar Georesour Geotechnol 28:324-344

49. Tarawneh B (2013) Pipe pile setup: database and prediction model using artificial neural network. Soils Found 53:607-615 
50. Skov R, Denver H (1988) Time-dependence of bearing capacity of piles. In: Proceedings third international conference on the application of stress-wave theory to piles Ottawa, pp 25-27

51. Long J, Kerrigan J, Wysockey M (1999) Measured time effects for axial capacity of driven piling. Trans Res Rec J Trans Res Board 1663:8-15

52. York D, Brusey W, Clemente F, Law S (1996) Setup and relaxation in glacial sand. Discussions and closure. J Geotech Eng 122:1498-1513

53. Svinkin MR, Skov R (2000) Set-up effect of cohesive soils in pile capacity. In: Proceedings, 6th international conference on application of stress waves to piles, pp 107-111

54. Tarawneh B, Imam R (2014) Regression versus artificial neural networks: predicting pile setup from empirical data. KSCE J Civil Eng 18:1018-1027

55. Xia T, Wang W, Wang XN (2010) Artificial neural network model for time-dependent vertical bearing capacity of preformed concrete pile. Applied mechanics and materials. Trans Tech Publ, Switzerland, pp 226-230

56. Pal M (2011) Modelling pile capacity using generalised regression neural network. In: Proceedings of Indian geotechnical conference, Kochi, Indlandi

57. Momeni E, Nazir R, Armaghani DJ, Maizir H (2015) Application of artificial neural network for predicting shaft and tip resistances of concrete piles. Earth Sci Res J 19:85-93

58. Maizir H, Kassim KA (2013) Neural network application in prediction of axial bearing capacity of driven piles. In: Proceedings international multiconference of engineers and computer scientists. IMECS, Hong Kong

59. Momeni E, Nazir R, Armaghani DJ, Maizir H (2014) Prediction of pile bearing capacity using a hybrid genetic algorithm-based ANN. Measurement 57:122-131

60. Baziar MH, Kashkooli A, Saeedi-Azizkandi A (2012) Prediction of pile shaft resistance using cone penetration tests (CPTs). Comput Geotech 45:74-82

61. Alkroosh I, Nikraz H (2012) Predicting axial capacity of driven piles in cohesive soils using intelligent computing. Eng Appl Artif Intell 25:618-627

62. Shahin MA (2010) Intelligent computing for modeling axial capacity of pile foundations. Can Geotech J 47:230-243

63. Alkroosh I, Nikraz H (2014) Predicting pile dynamic capacity via application of an evolutionary algorithm. Soils Found 54:233-242

64. Shioi Y, Fukui J (1982) Application of N-value to design of foundations in Japan. In: Proceeding of the second European symposium on penetration testing, pp 159-216

65. Alavi AH, Aminian P, Gandomi AH, Esmaeili MA (2011) Genetic-based modeling of uplift capacity of suction caissons. Expert Syst Appl 38:12608-12618

66. Rahman M, Wang J, Deng W, Carter J (2001) A neural network model for the uplift capacity of suction caissons. Comput Geotech 28:269-287

67. Ryan TP (2008) Modern regression methods. Wiley, New York

68. Gandomi AH, Alavi AH (2012) A new multi-gene genetic programming approach to nonlinear system modeling. Part I: materials and structural engineering problems. Neural Comput Appl 21:171-187

\section{Submit your manuscript to a SpringerOpen ${ }^{\circ}$ journal and benefit from:}

- Convenient online submission

- Rigorous peer review

- Open access: articles freely available online

- High visibility within the field

Retaining the copyright to your article

Submit your next manuscript at $\mathbf{s p r i n g e r o p e n . c o m ~}$ 